\title{
3D modeling of the fracture zones to decipher foundation level at Barethi Super Thermal Power Project, Madhya Pradesh, India
}

\author{
Rashtrapal H Chavhan and Vishal V Sakhare \\ Geological Survey of India \\ Nagpur, India \\ rashc1001@rediffmail.com
}

\begin{abstract}
The proposed 6x 660 MW Super Thermal Power Project is located near village Sandni and Barethi in Rajnagar Tehsil of Chhatarpur district, Madhya Pradesh. The terrain belongs to Bundelkhand Granite Massif (BGM) comprising a variety of medium to coarse grained granites. The Project site is mainly covered with soil/overburden material barring a few sporadic outcrops of granites. The drill cores and Rock Quality Designation (RQD) are important tools to decipher subsurface information. Moreover, RQD provides a quantitative assessment of subsurface geology. Therefore, an attempt has been made to decipher the subsurface fracture zones from RQD and drill cores to develop a 3D model to know the continuity of the fracture zones. This will help to keep the foundation in competent rock mass avoiding fracture zones.

The Inverse Distance weighted (IDW) anisotropic modelling method has been used to validate the drill core data in respect of fracture zones. Depth of fracture zones determined from drill cores with $\mathrm{RQD}<\mathbf{2 0} \%$ have been considered in the model to determine thickness of fracture zones and its lateral continuity in 2D as well as 3D perception to decipher the foundation level of the Superstructure.
\end{abstract}

The mechanical breakage and weathered rock mass have been eliminated during modeling the fracture zone. The model indicates that "Very Poor RQD domain $(R Q D<20 \%)$ is interpreted as fracture zones, "Poor" RQD domain (RQD 20$\mathbf{4 5} \%$ ) corresponds to less fractured rock mass. The study also revealed that "Fair RQD (45-65) and "Good" RQD domains $(>65 \%)$ indicate a gradational contact i.e. Fair RQD rock mass isgradually becoming Good $R Q D$ rock mass away from the fractures zones. Thus the model has established a relationship between subsurface fracture zones and RQD.The fractures zones may have developed due to the effect of a series of sympathetic fault zones occupy by quartz reefs, doleritic dykes, pegmatite and quartz veins within BGM under soil cover. The model confirms that the RQD within the area of critical structures of the project ranges from Fair to Good category indicating competent rock mass. A few drill holes have been suggested away from the fracture zone to validate the model as well as to increase the confidence level.This model can be utilized for conceptual understanding of the fracture zone in 3D perception to decipher the foundation of heavy civil engineering structures like irrigation andhydroelectric projects (dam, power house etc.), thermal project, heavy industries etc. This will also help to have an idea on in-situ engineering properties /qualities of rock mass as well as adopt suitable excavation methodology to reach the foundation level. The model can give a better visualization of sub-surface geological conditions to fix the foundation levels of different components, to work out the excavations methodologies and helps in timely implementation of the project without time and cost over runs.

Keywords-BGM; BGC; IDW, 3D modeling; NTPC.

\section{INTRODUCTION}

National Thermal Power Corporation (NTPC), a Government of India Enterprises, has planned to install a State of the art "Barethi Super Thermal Power Project (6X660 MW)" near village Sandni and Barethi in Rajnagar Tehsil of Chhatarpur district, Madhya Pradesh. The site is located at a distance of about $25 \mathrm{~km}$ from Chhatarpur and is approachable from Basari by $5 \mathrm{~km}$ situated on ChhatarpurPanna NH-75 road.

The investigation of the subsurface conditions at the thermal power plant site is an important aspect of the site evaluation process and continued for all stages (Prefeasibility to construction stages). This provides information or basic data for deciding the nature and condition of subsurface geology as well as to demarcate the suitable area and depth for foundation of different components. Again, adequate geotechnical investigations are neededto establish competency of the foundation media for the installation of different components under all static and seismic loading conditions. Detailed investigations provide geological (surface and sub-surface) and geotechnical information that serve as an input parameter for the safe design of a project, in present case the thermal power plant structures, systems and components.

Fractured areas lithologically are continuous and structurally are anisotropic (different properties and different directions) in the upper crust of the earth[2]. Generally, the geologically disturbed areas are mechanically related to fracturing systems, minor faults/shears, and joints. These fractured regions can vary from one area to another, so that the centre of the faulted areas is more fractured. Based on the structural studies, damage zones can reveal the properties of rocks within the fault trends ([3], [4], [8]).

Conversely, low information usually obtained by field surveys which can just produce the surface geological map and cannot characterize the properties of exact fault systems in $3 \mathrm{D}$ models[6]. The difficulties of trend determination of some faults are moredifficult when the outcrops are discontinuous and undistributed continuously, or the trend 
faults are covered on the surface by soils/overburdens. RQD will also vary with direction, because of variation in discontinuity frequency with direction.

The present paper deals with core logging, conceptual 2D and 3D model of RQD by geostatistical method in order to find relationship between the generated RQD model and fracture zones. 3D model enables to visualise the trendsof sub-surface fracture zone and its effect on RQD percentage to interpret and establish foundation levels of critical structure like turbo-generator and chimney areas. The uncertainty within the area was calculated for introduction of new points to undertake drilling for quantifying the uncertainty involved in this phase of exploration and producing a map from the viewpoint of fracture zones. Moreover, the measure of uncertainty, in addition to predicted values, satisfies a certain criterion which was provided.

\section{GEOLOGY AND STRUCTURAL SETTING}

The BundelkhandGranitiod Complex (BGC) of the Precambrian has undergone deformation and metamorphism prior to its becoming a stable cratonic platform in the Proterozoic period .

The Bundelkhandgranitiod Complex is flanked along its southern and northwestern margin by the PreVindhyans siliciclastic shelf sequence - the Bijawar Formation. However lenticular Bijawar sequence of volcanosedimentary is present above Vindhyan sequence on the southern side. Both these groups of rocks are resting over the BundelkhandGranitoid Complex (Fig 1). The west, south and east margin of Bundelkhandgranitiod Complex are covered by the vindhyans rocks, while northern border is covered under alluvium.

It is mentioned that the BGC and Vindhyan are bounded by two major tectonic lineaments i.e. Son-Narmada lineament to the south running east-west and Indo-Gangatic trough to its north. The rocks of the area comprise metasediments, meta-volcanic granite and basic intrusive. The oldest rocks amphibolite and migmatite have undergone deformation and medium grade metamorphism and occurs as enclaves within the rocks of later period of granitic composition. Older metamorphic later injected by doleritic and basaltic magmas along the fracture joints during a period of deformation [9].Faults and fractures system in the area are noted in NE-SW and NW-SE directions (Fig.1) while ENE-WSW shearing are recorded with surface manifestation of sulphide mineralistion, veintlets of chalcopyrite , pyrite, development of gossan, and covellite in the mylonitised rock [9]. Fig.2 show counter plan with bore holes location in chimney and Turbo-generatorareas.

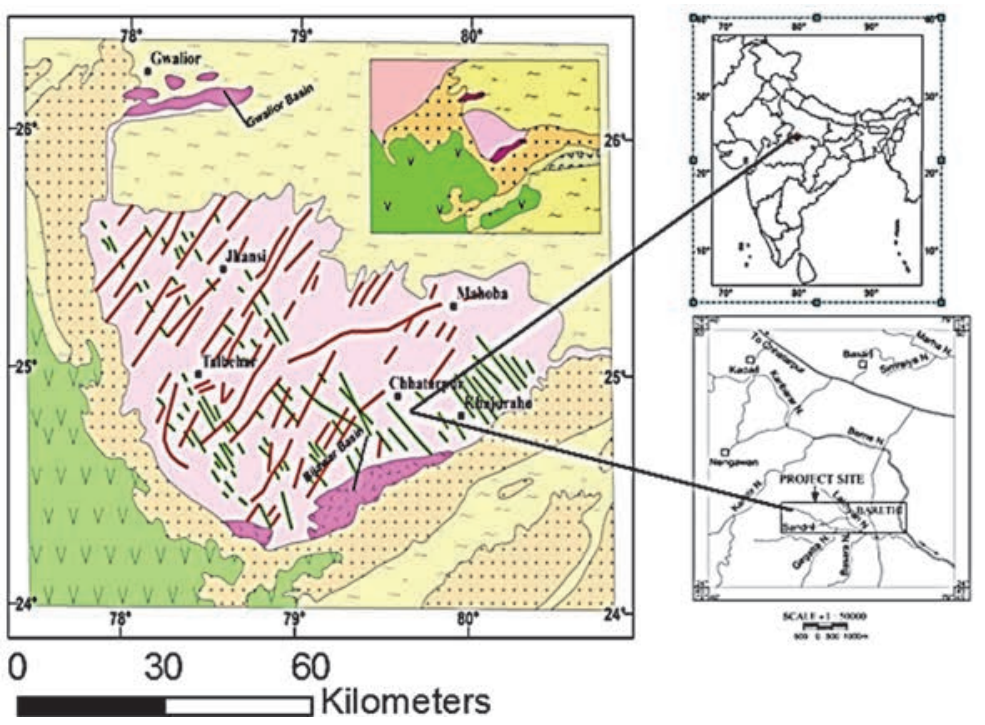

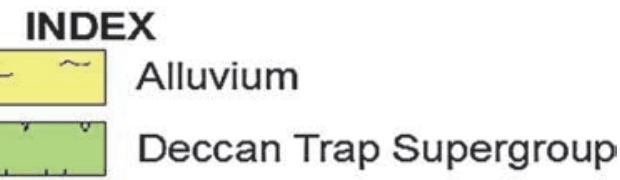

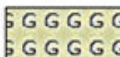

\section{Gondwana Supergroup}

$\therefore::$ Vindhyan Supergroup

Bijawar Group

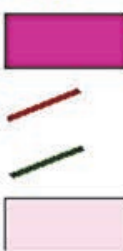

Gwalior Group

Qtz_reef

Dyke

Granite

Fig.1 Generalised geological map (after Basu ${ }^{1}$, 1987) of Bundelkhand Granite Massif (BGM) showing the disposition of dykes and quartz reefs. (Inset) Map showing BGM, Vindhyan Basin and other geological features

\section{RQD IN CRITICAL COMPONENT OF SUPER THERMAL POWER PLANT}

The rock quality designation (RQD) is a commonly used index for the description of rock mass fractures state. The RQD was mainly introduces for civil engineering applications, and it has been quickly adopted in mining engineering as well. However, this also leads to a number of limitations, including among other, a dependency of the RQD value on the borehole orientation with respect to foliation/bedding joints and other joints and on the selected threshold value for the minimum intact core length. RQD application has been extended to other areas of rock mechanics, and it has become a fundamental parameter in geotechnical engineering [7]. The success of the RQD is due to its simple definition, which is the ratio of intact core pieces longer than $10 \mathrm{~cm}$ with drilling length and expressed in percentage.

RQD is a directionally dependent parameter and its value may change significantly, depending upon the borehole orientation. It is intended to represent the rock mass quality 
in situ. However, quality of drilling is also an important function of RQD, that's why it is always suggested to usegood diamond bits and drilling machine. When using diamond core drilling, care must be taken to ensure that fractures, which have been caused by handling or the drilling process, are indicated and omitted when determining the value of RQD.Runwise RQD encountered in bore holes shown in Fig. 3. RQD in weathered rock should not be considered for statistical analysis and modelling. Classification of rocks according to Deere is represented in Table I

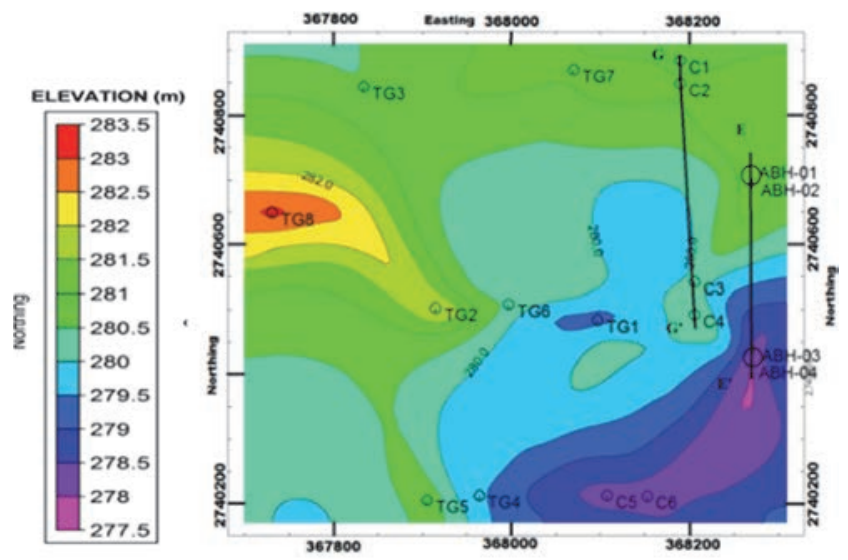

Fig.2 Contour plan showing section lines ( $\mathrm{EE}^{\prime}$ and $\left.\mathrm{GG}^{\prime}\right)$ along the proposed chimneyand turbo-generator areas with proposed new drill hole points (ABH-01 toABH-04) of Thermal Power Plant

TABLE I. CLASSIFICATION OF ROCK BY THE RANGES OF RQD [4].

\begin{tabular}{|l|l|}
\hline \multicolumn{1}{|c|}{ RQD (\%) } & \multicolumn{1}{c|}{ Rock quality } \\
\hline$<25$ & Very poor \\
\hline $25-50$ & Poor \\
\hline $50-75$ & Fair \\
\hline $75-90$ & Good \\
\hline $90-100$ & Excellent \\
\hline
\end{tabular}

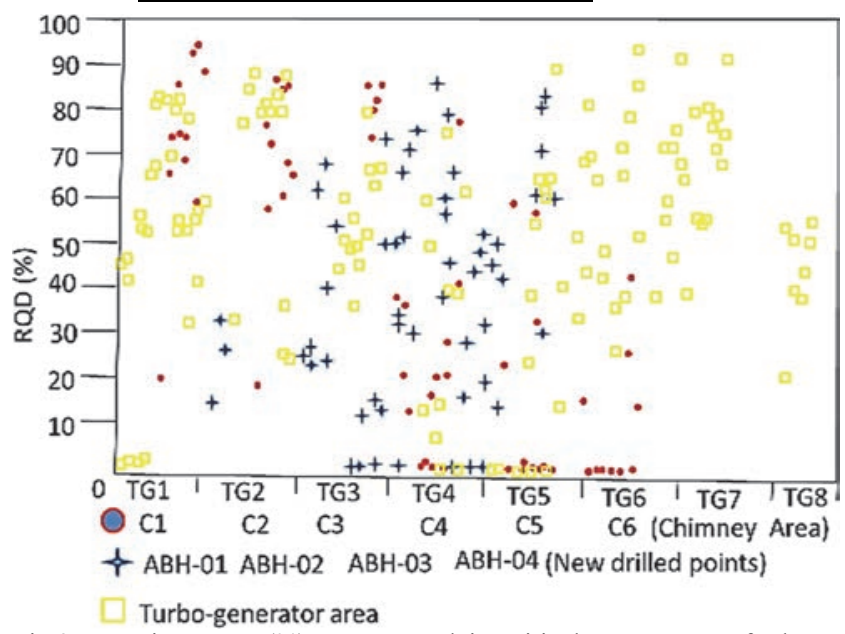

Fig.3 Runwise RQD (\%) encountered in critical component of Thermal Power Plant

\section{A. Descriptive statistics of RQD}

Chimney 1(borehole $\mathrm{C} 1$ and $\mathrm{C} 2$ ) and chimney 2 (borehole $\mathrm{C} 3$ and $\mathrm{C} 4$ ) (Fig 2) having $50 \mathrm{~m}$ diameter and $20 \mathrm{~m}$ depths each have been assessed to know subsurface geology, which encountered fracture zones in chimney area viz: $\mathrm{C} 3$ and $\mathrm{C} 4$.

A summary of descriptive statistics of the RQD samples is presented in Table 2. For a total of 304 estimates, measured minimum and maximum values of RQD in the wells area $0 \%$ and $93 \%$ respectively. The resulting mean value for RQD is 41.98 , with a standard deviation of 30.45 and sample variance of 927.573 . The frequency distribution has skewness of -0.10 (Mean $<$ Median) indicate that data is skewed left and kurtosis of - 1.355 value signify, flatter peak and lighter tailsconsidering "Zero" as the mode valve.

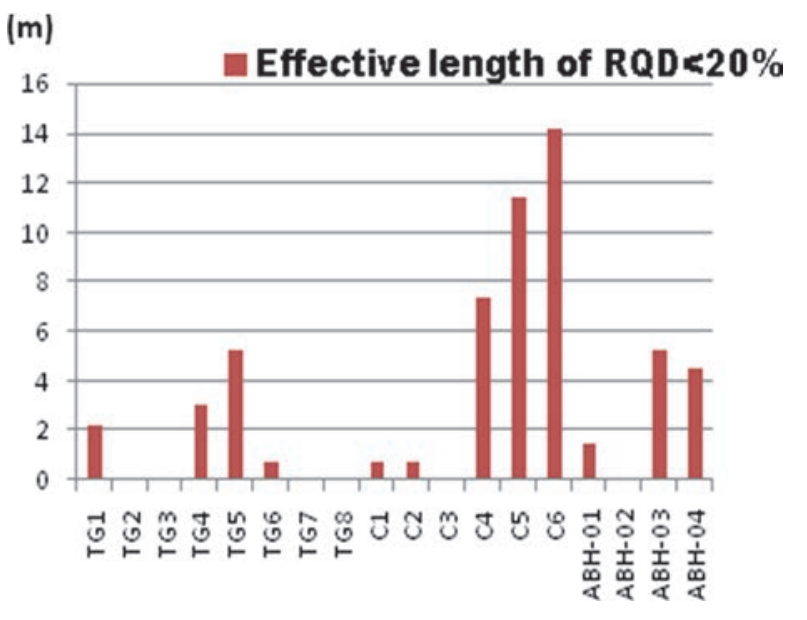

Fig 4. Effective length of RQD $<20 \%$ in an individual drilled depth (TG1 to C6 -each drilled depth $20 \mathrm{~m}$ and $\mathrm{ABH}-01$ to $\mathrm{ABH}-04$ - each $25 \mathrm{~m}$ drilled depth)

Considering the effect of fracture, RQD changes down depth in Turbo generator as well as chimney areas in an original location ( $\mathrm{C} 1$ to $\mathrm{C} 4)$ and suggested new boreholes at new points $(\mathrm{ABH}-01$ to $\mathrm{ABH}-04)$ that show substantially improved in RQD away from the original location i.e. in therevised lay out plan.Fig 4 Signify effective length of RQD $<20 \%$ and fig 5 show RQD behavior $<20 \%$ drill holes in anindividual drilled length for different boreholes.Statistics of RQD.

TABLE II: DESCRIPTIVE PARAMETER OF RQD (\%) WITHIN CHIMNEY AND TURBO-GENERATOR AREASTATISTICAL PARAMETER

\begin{tabular}{|l|l|}
\hline & \multicolumn{1}{|c|}{ Amount } \\
\hline Count & 304 \\
\hline Minimum & 0 \\
\hline Maximum & 93 \\
\hline Mean & 41.98 \\
\hline Mode & 0 \\
\hline Kurtosis & -1.355 \\
\hline Standard deviation & 30.45 \\
\hline Skewness & -0.10 \\
\hline Sum & 12805 \\
\hline Median & 45.5 \\
\hline Sample variance & 927.573 \\
\hline Range & 93 \\
\hline
\end{tabular}

Starting at the top of the hole and moving down the hole in 1 meter increments, new intervals has been interpolated 
based on a weighted-distance from the original intervals (i.e. closer original intervals have a greater weight on the new estimation). A new interval has been interpolated for the entire length of the borehole regardless of their distance from an original interval.The Inverse-Distance Anisotropic modelling method is one of the important tools of the Inverse-

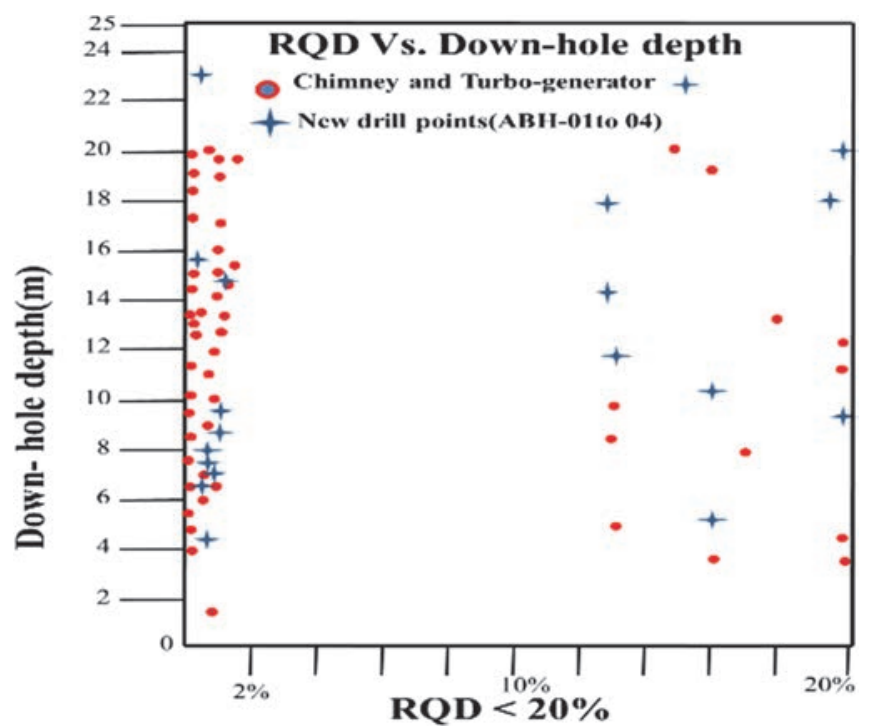

Fig.5 Scatter plot RQD $(<20 \%)$ Vs. down hole depth

Distance algorithm. Using Inverse-Distance in general, a voxel nodevalue is assigned based on the weighted average of neighbouring data points, and the value of each data point is weighted according to inverse of its distance from the voxel node, taken to a power (an exponent of "2" = InverseDistance squared, "3" = Inverse-Distance cubed, etc.). The greater the value of the exponent, the less influence distant control points will have on the assignment of the voxel node value.

Using the Inverse-Distance Anisotropic method, the program will look for the closest control point in each 90degree sector around the node. For this method, the weighting exponent is also set to " 2 ". This kind of directional search can improve the interpolation of voxel values that lie between data point clusters, and can be useful for modeling drill-hole based data for excavation/piling of heavy civil structure. The quadrant searching tends to connect highs and lows at the same elevation.

TABLE III: CATEGORISATION OF 3D FRACTURE ZONE

\begin{tabular}{|l|l|l|}
\hline \multicolumn{1}{|c|}{ RQD } & \multicolumn{1}{c|}{ Area } & \multicolumn{1}{c|}{ Fracturing } \\
\hline$<20$ & Fracture & High \\
\hline $20-45$ & Non fracture & Low \\
\hline$>45$ & Gradual & Normal \\
\hline
\end{tabular}

\section{B. Geostatistical method}

In 2D/3D modelling, the basic statistical principle of Krigging Algorithm is used. For creating the 3D model in UTM grid, the XY coordinate data (Northing/Easting) of boreholes with $\mathrm{Z}$ coordinates i.e. RL (Reduced Level) are used.
In 2D model, each smallest distinguishable square unit is pixel. The smallest distinguishable box shaped part of 3 dimensional image is called voxels i.e. volume pixel. In other words, a voxel is a three dimensional grid.For creating 2D and 3D maps, this principle of voxel is used. Drilled core logs data, lithology layer slices at different depths were prepared in Turbo-generator and Chimney areas to understand the

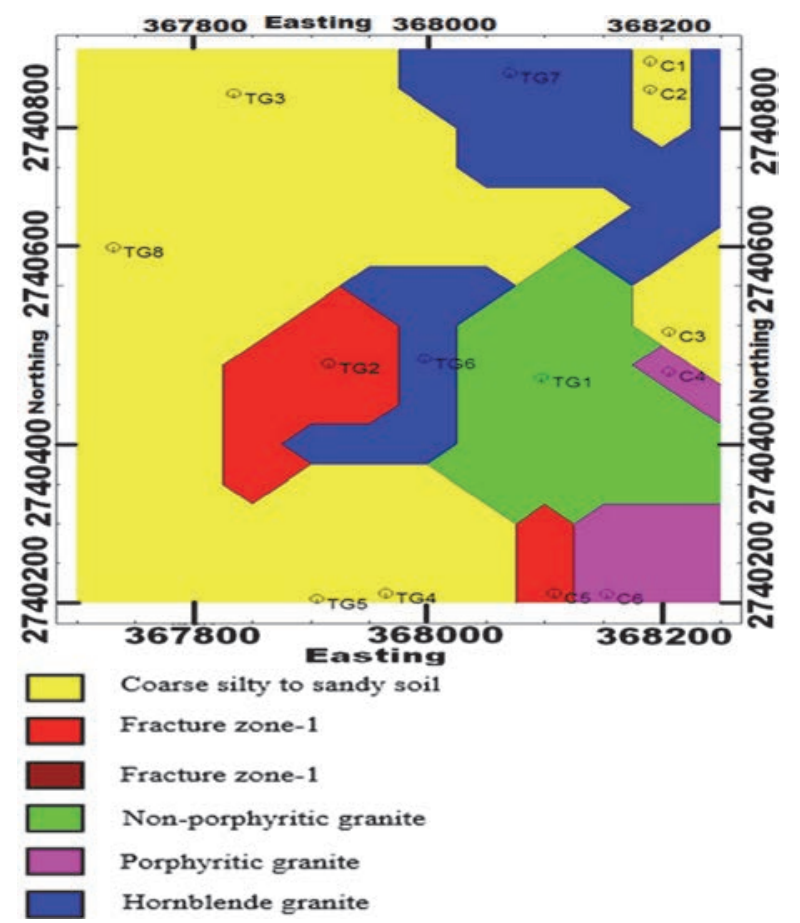

Fig.6 Lithology slices at $7.0 \mathrm{~m}$ and $8.0 \mathrm{~m}$ depth encountered fracture zone 1 in Turbo-generator area.

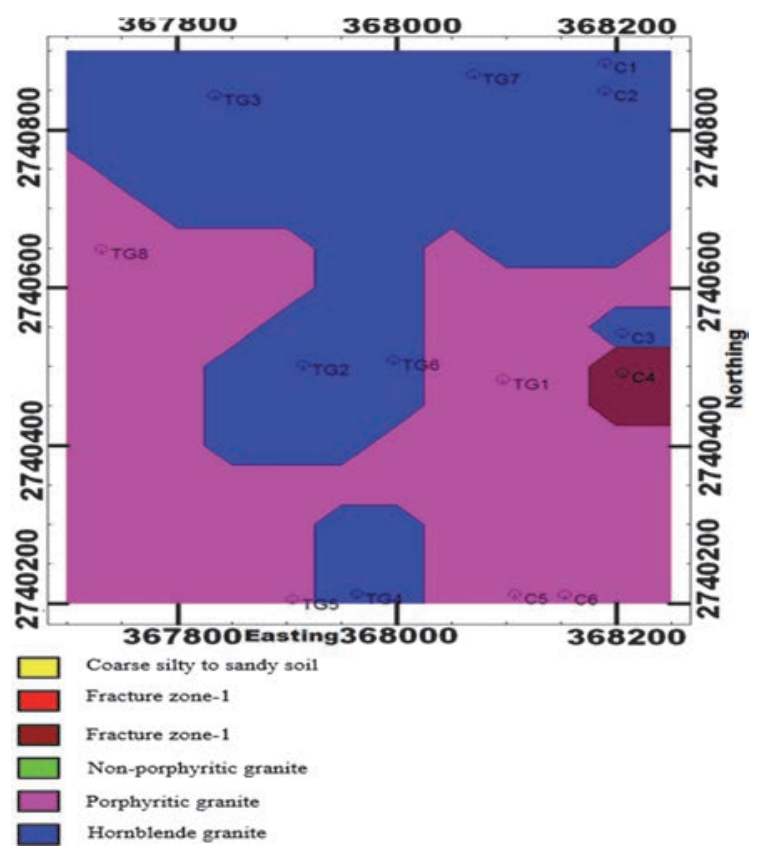

Fig.7 Lithology slices at $20.0 \mathrm{~m}$ depth encountered fracture zone 2 in Chimney area. 
nature of strata and fracture patterns (Fig. 6 to 7).Rock fractures are considered as a non- systematic discontinuous feature of rock masses. They are not in sets or parallel. They could be large in term of numbers but theirdistribution is

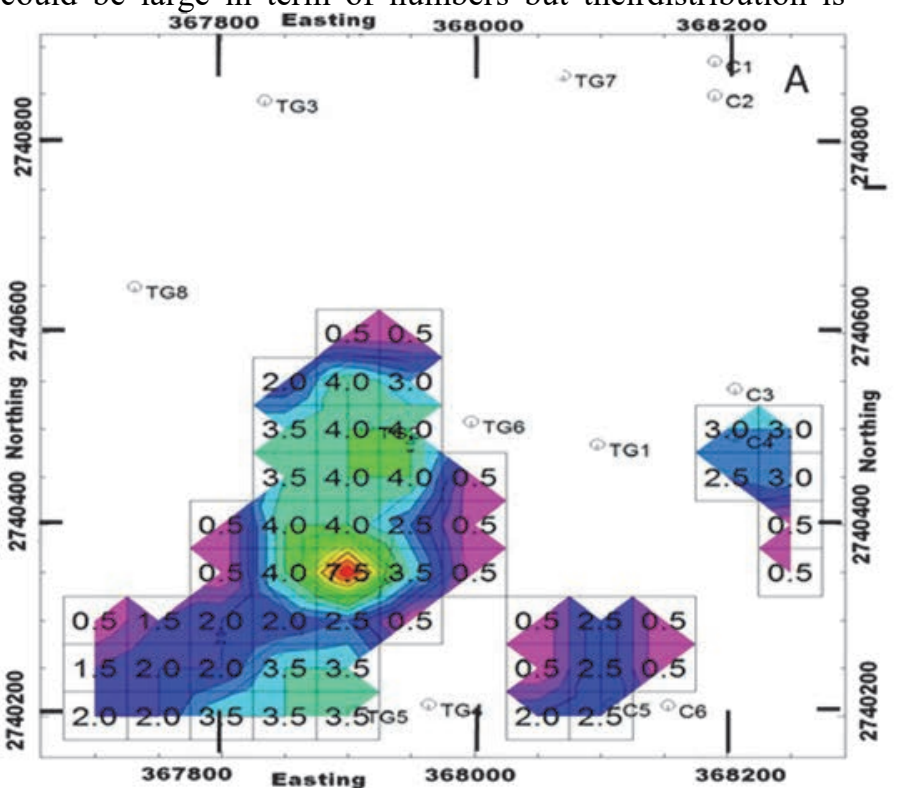

generally random. Rock mass quality is influencedby the number of rock fractures and they are usuallyconsidered in the overall degree of fracturing of a

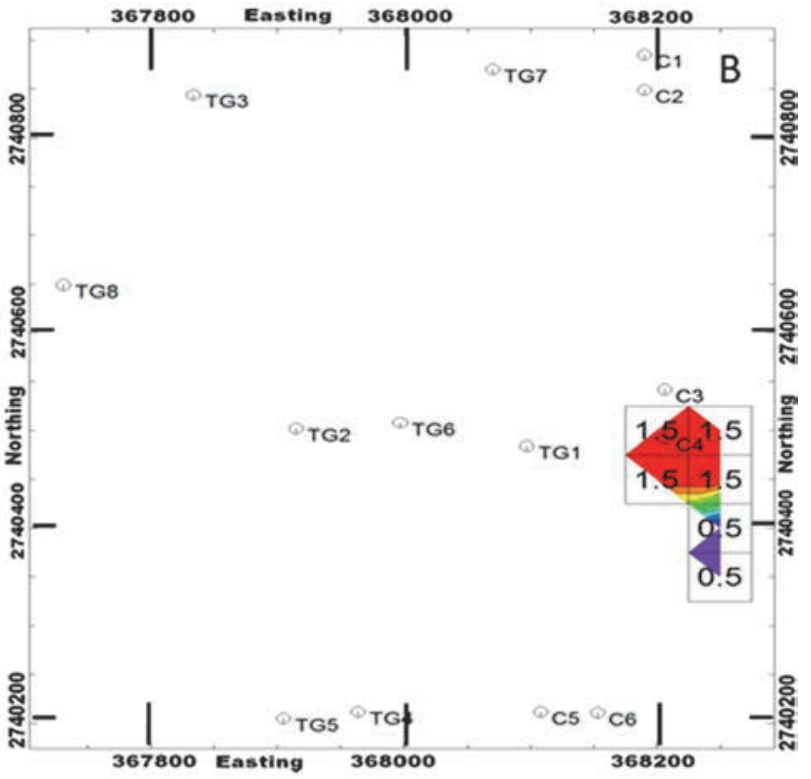

Fig.8 (A-B). 2D model indicate thicknes and influence of fracture zones (1 and 2) and its lateral extents in critical component of Thermal Power Plant

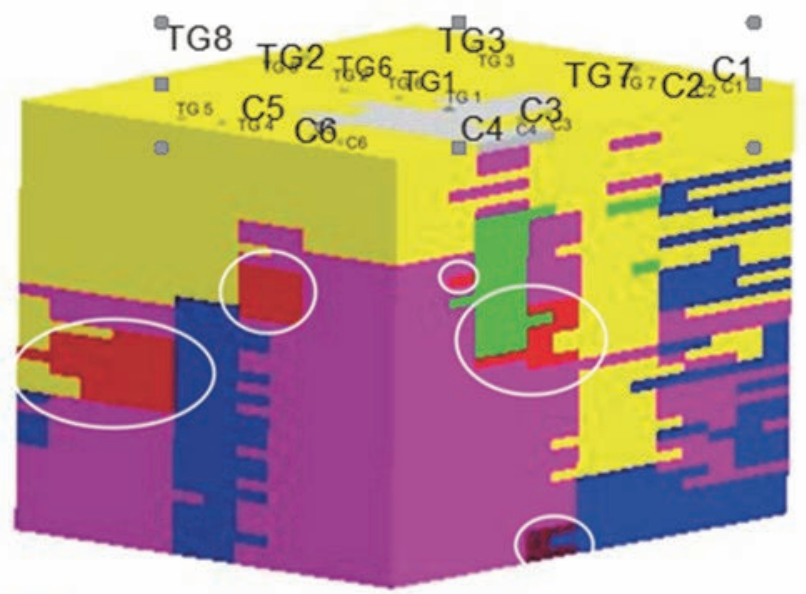

Coarse silty to sandy soil

Fracture zone-1

Fracture zone-1

Non-porphyritic granite

Porphyritic granite

Hornblende granite

\section{Pegmatite}

Fig 9. 3D model of fracture zones in original locations of Chimney area (Decomposed/ disintegrated (W5) rock akin to silt and sandy soil

rock mass, in term of joint spacing and RQD. Fracturing of a rock mass is represented in 2D modelling to interpret thickness of fracture zones at different depths by producing Iso-surface maps, which give an idea of thickness of two fracture zones at various depths (Fig.8A and 8B). The thickness of fracture zone 1 in borehole TG2 is $7.5 \mathrm{~m}$ and its thickness decreases away from the fracture zone1 to as much as $0.5 \mathrm{~m}$ (Fig 8A)and for fracture zone 2 the thickness in borehole $\mathrm{C} 4$ is $1.5 \mathrm{~m}$ and decreases to $0.5 \mathrm{~m}$ laterally (Fig $8 \mathrm{~B})$. Using fracture data, Iso-surface maps were also prepared to have an idea of $3 \mathrm{D}$ view of fracture zones at depths (Fig 9). Iso-surfaces maps are smooth, hollow data shells representing the single value from the voxel model.

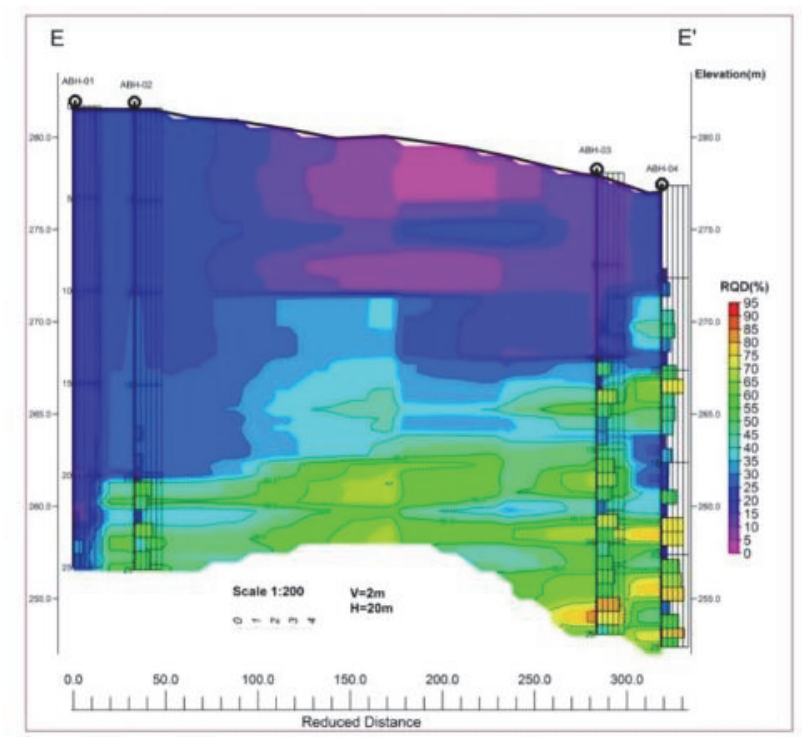

Fig.10. Distribution of RQD (\%) at proposed new location of drillholes of critical component (chimney) of Thermal Power Plant 


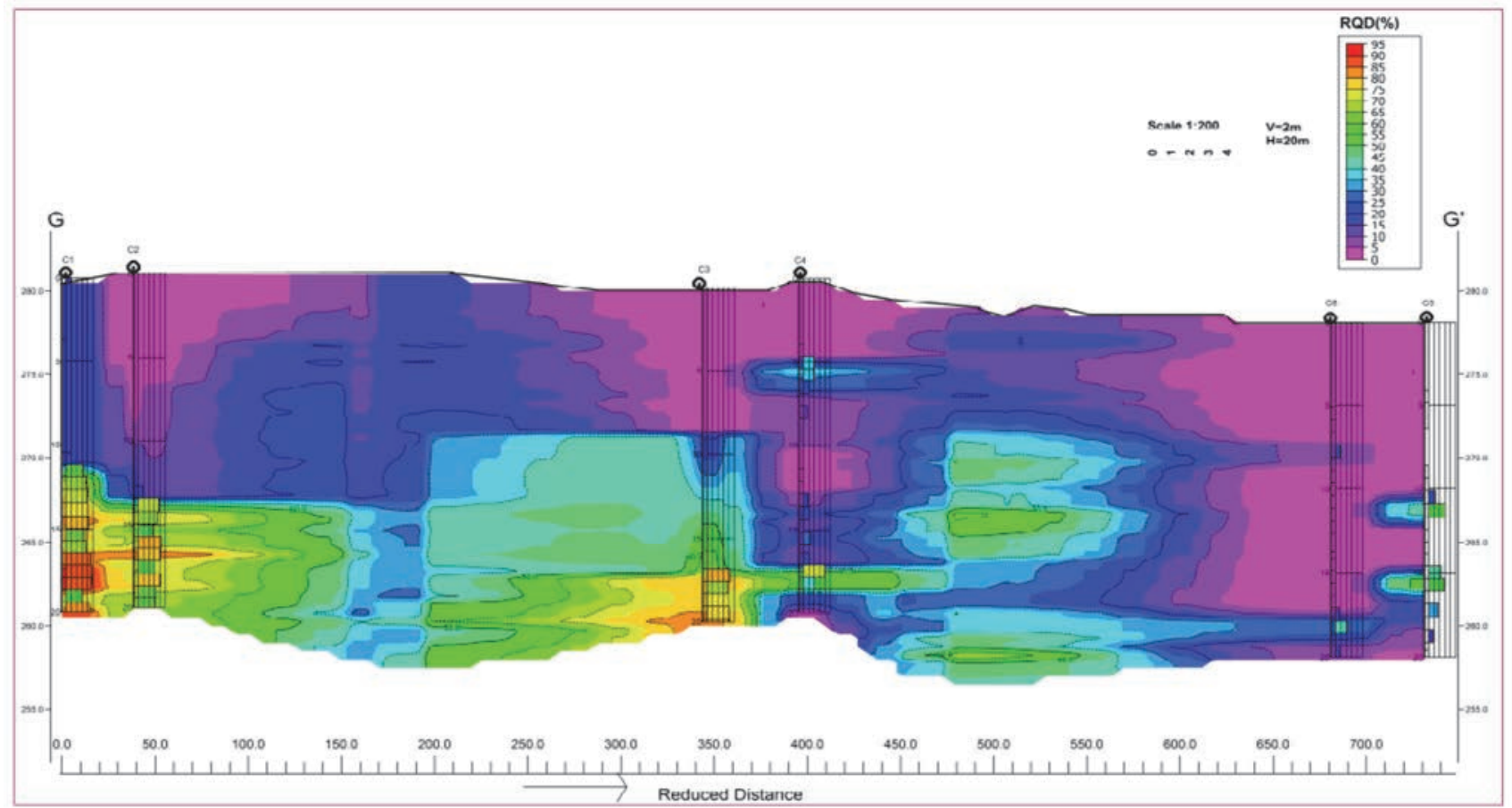

Fig.11. Distribution of RQD (\%) in a original location of Chimney area
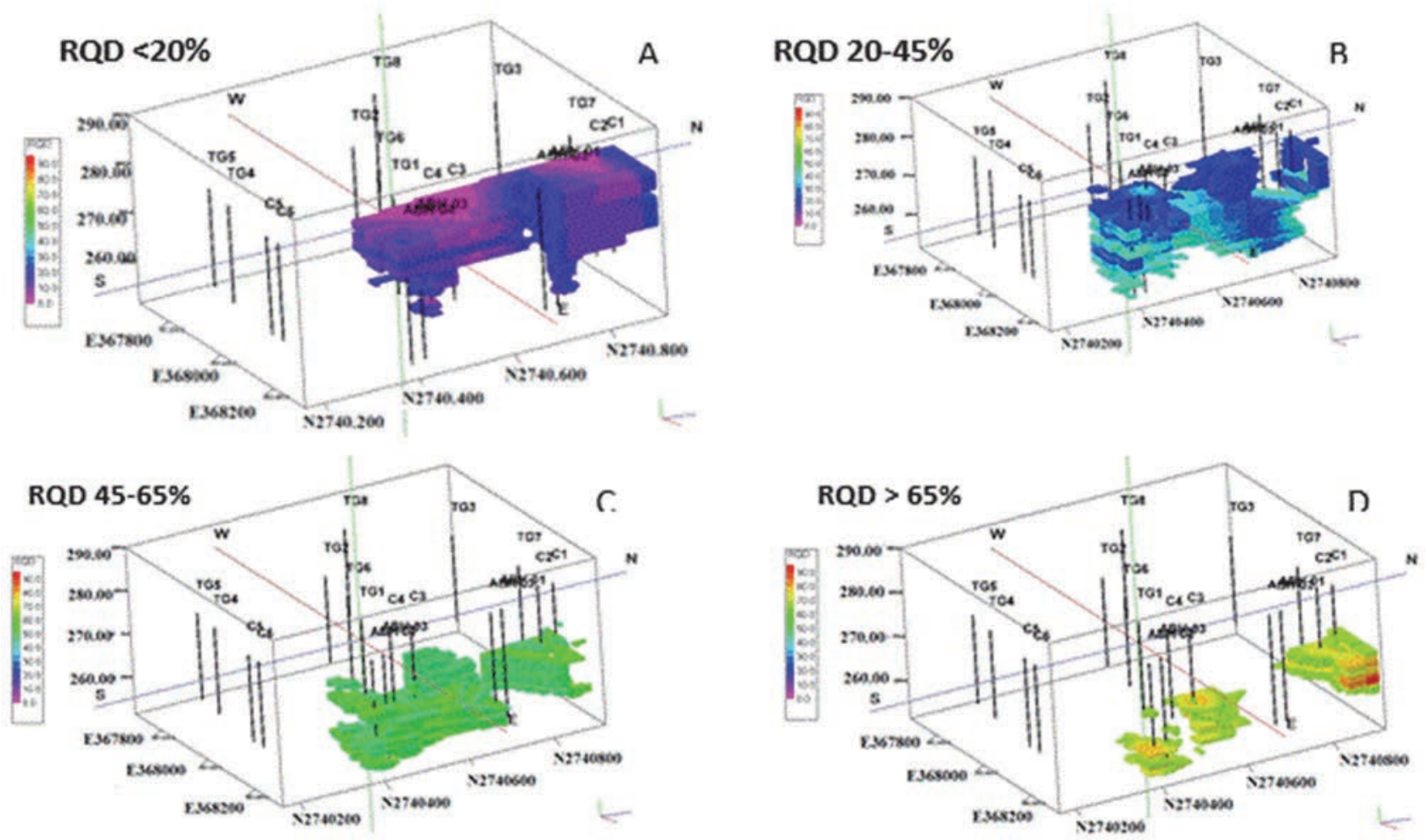

Fig. 12 (A-D). 3D model showing RQD (\%) encountered down depth in proposed new drill points. 


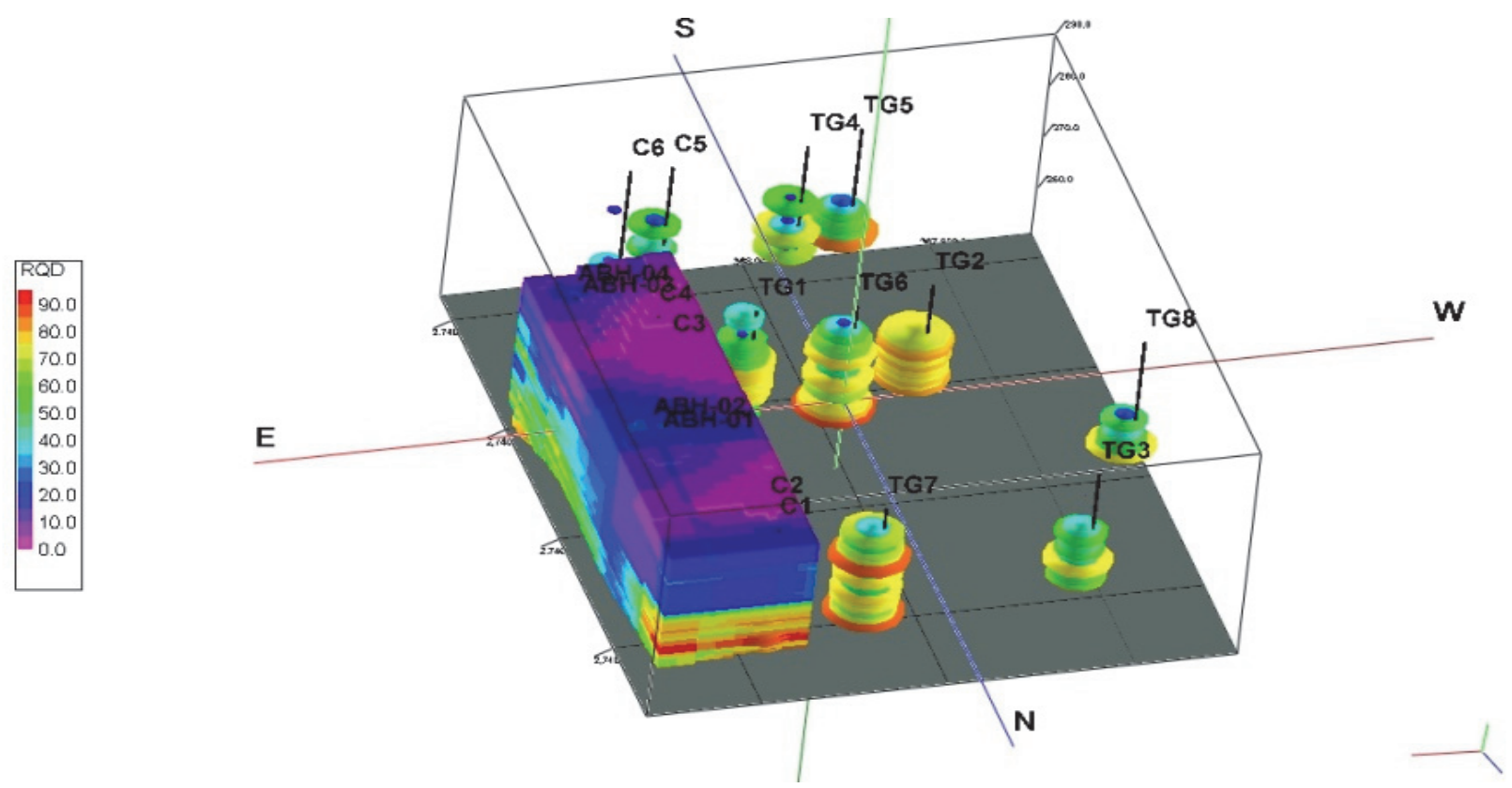

Fig13. Combined model created for RQD (\%) encountered in proposed new drill points and RQD(\%) in original drill points represented as oblate shape

\section{FRACTURE DETECTION IN 3D}

Based on fracture zones encountered in different boreholes, a three-dimensional model is created to interpret the influence of fracture zones within chimney and Turbogenerator areas. The model signifies presence of two fracture zones. The fracture zone1 intersected at drilled holes TG2, TG5 and C5 starts from $5 \mathrm{~m}$ depth and continue up to $13 \mathrm{~m}$ below ground level and fracture zone 2 intersected in drill holes $\mathrm{C} 4$ at two places i.e. from $8.5 \mathrm{~m}$ to $11 \mathrm{~m}$ and $18.65 \mathrm{~m}$ to $20 \mathrm{~m}$ below ground level (Fig.9). Fracturing of rock mass have been classified based on RQD (\%) encountered at different boreholes and intermittent areas have been interpolated in a sections as shown in Fig 10 and 11, show behaviour of RQD (\%) at different level.

\section{PROPOSED NEW POINTS LOCATION}

To validate the model, new drill holes have been proposed at new location to understand behaviour of fracture discontinuity and its effect on RQD (\%) and interpolated the RQD in the intermediate area of the proposed points. The coordinates of the new holes drilling are represented in Table 4.As can be seen in the Fig.12 (AD) the amounts of RQD (\%) in the new drill holes are high and validating the suitable location for foundation of critical structures of the Thermal Power Plant.

\section{CONCLUSIONS}

Bundelkhand granite complex is a massive batholithic intrusion mainly comprises of variant of medium to coarse grained granites exposed in a soil covered as isolated patches at the Project site. Sub-surface exploration (drill core) data revealed two fracture zones at proposed location of Turbo-generator and Chimney areas. RQD \% determined in fracture zone indicate "Very Poor" rock mass quality in an intermittent down depth bore holes.RQD $<20 \%$ determinedin bore holes TG1, TG4, TG5 TG6, C1 C2, C4 and $\mathrm{C} 6$ where non-porphyritic granite, porphyritic granite and mafic rich granite have been encountered.Subsequently to negate this location, drill holes (ABH-01, ABH-02, ABH03 and $\mathrm{ABH}-04)$ are suggested in new location to understand nature of fracture and its intensity and its effect on the quality of rock

TABLE IV: THE PROPOSED LOCATION OF NEW DRILL HOLES

\begin{tabular}{|l|l|l|}
\hline \multicolumn{1}{|c|}{ Point } & \multicolumn{1}{|c|}{ Northing } & \multicolumn{1}{c|}{ Easting } \\
\hline BH-01 & N2740721 & E368269 \\
\hline ABH-02 & N2740694 & E368271 \\
\hline ABH-03 & N2740439 & E368272 \\
\hline ABH-04 & N2740413 & E368269 \\
\hline
\end{tabular}

mass determined in terms of RQD \% for foundation level of critical structure.Coarse to medium grained pink granite dominantly of pink feldspar are encountered in the boreholes at new locations.To validate this model for determination of fracture zone, the new area (location) away from the fracture zones, 2D, 3D and geostatistical method have been selected.The new points location validated from the model are found to be best suitable for foundation level and for designing the excavation methodology during construction.Though sub-surface explorations through drilled holes give point data information but, sub-surface geology of an area has been depicted through this model in a better minimising uncertainties. Therefore, this model has proved its efficacy with enhanced confidence level. The same model can be used in Water resource development, thermal, nuclear and other major civil engineering projects, especially in hard rock igneous terrain for evaluations of the 
foundation conditions, determination of depth of foundation as well as for optimisation of excavation methodologies well in advance. This will facilitate timely implementation of the project without time and cost over runs.

\section{ACKNOWLEDGEMENT}

The authors acknowledge the Director General, GSI for financial support and encourage publishing this paper. Shri N.Kutumba Rao, Additional Director General, GSI, Nagpur is acknowledged for his constant support to write the paper. The authors would like to thank Shri B.K. Bhandaru Deputy Director General, Regional Mission Head -Mission-IV and Shri Prashanta Mishra Deputy Director General, Regional Mission Head -Mission-I for critically going through the manuscript, last but not least, authors would like to thank Data Code, Nagpur office for providing the Geo soft software liaison.

\section{REFERENCES}

[1] Basu, A.K,'Geology of parts of Bundelkhand"Granitemassif, Central India, Rec.geol.Surv, India, 1987, 117, 61-124

[2] Caine JS, Evans, JP, Forster CB (1996) "Fault zone architecture and permeability structure." Geology 24:1025-1028.

[3] Chester FM, Logan JM (1987) “Compositeplanar fabric of gouge from the PunchbowlFault, California.” Jour.Struct Geo 19, pp621-634.

[4] Chester FM, Evans JP, Biegel RL (1993) "Internal structure and weakenin mechanism of the San Andreas fault." Jour.Geophys Res 98, pp 771-789.

[5] Deere DU (1989) "Rock qualitydesignation (RQD) after 20 years." U.S.Army Corps Engrs Contact Report GL-89-11. Waterways Experimental Station, Vicksburg, MS.

[6] Escuder, Viruetea et. al. (2003) "3Dstochastic modelling and simulation of faultzones in the Albala granitic plutons, SWIberain Massif." Jour.Struct Geol 25:1487-1506.

[7] ]Hoek, E. and Brown, E.T. (1980) "Underground excavation in Rock",Institution of Mining andMetallurgy, London.

[8] Schulz SE, Evans JP (2000) "Mesoscopicstructure of the PunchbowlFault, Southern and the geologic andgeophysical structure of active strike slipfaults.” Jour.Struct Geo 22, pp 913-930.

[9] Singhai, RK and Jain, AK (1984) "Reporton geological mapping of the BundelkhandGranite in parts of Chhatrapur District,GSI." Unpub. Report. 